\title{
Restoration of adiponectin expression via the ERK pathway in TNF $\alpha$-treated 3T3-L1 adipocytes
}

\author{
EUGENE CHANG $^{1 *}$, JUNG MOOK CHOI ${ }^{1 *}$, WON JUN KIM ${ }^{2}$, EUN-JUNG RHEE ${ }^{3}, \mathrm{KI} \mathrm{WON} \mathrm{OH}^{3}$, \\ WON-YOUNG LEE ${ }^{3}$, SE EUN PARK $^{3}$, SUNG WOO PARK $^{3}$ and CHEOL-YOUNG PARK ${ }^{1,3}$ \\ ${ }^{1}$ Diabetes Research Institute, Kangbuk Samsung Hospital, Sungkyunkwan University School of Medicine, Seoul 110-746; \\ ${ }^{2}$ Department of Endocrinology and Metabolism, Gangneung Asan Hospital, Ulsan University School of Medicine, \\ Gangneung 201-711; ${ }^{3}$ Division of Endocrinology and Metabolism, Department of Internal Medicine, Kangbuk \\ Samsung Hospital, Sungkyunkwan University School of Medicine, Seoul 110-746, South Korea
}

Received September 27, 2013; Accepted March 16, 2014

DOI: $10.3892 / \mathrm{mmr} .2014 .2278$

\begin{abstract}
Adiponectin and tumor necrosis factor- $\alpha$ (TNF- $\alpha$ ) exert opposite effects on obesity-associated inflammation and insulin signaling. The purpose of the present study was to investigate the effects of chronic TNF- $\alpha$ on adiponectin levels in 3T3-L1 adipocytes, as well as the potential reversal mechanisms. Differentiated 3T3-L1 adipocytes were exposed to TNF- $\alpha$ for three different incubation times and then to various wash-off periods with or without mitogen-activated protein kinase (MAPK) inhibitors. TNF- $\alpha$ significantly reduced adiponectin gene expression in a dose- and time-dependent manner and activated c-Jun N-terminal kinases (JNK), extracellular signal-regulated kinases (ERK) and p38 MAPK. A $16 \mathrm{~h}$ restoration period fully reversed the decrease in adiponectin levels following $16 \mathrm{~h}$ treatment with TNF- $\alpha$; however, $16 \mathrm{~h}$ withdrawal of TNF- $\alpha$ following 32 or $48 \mathrm{~h}$ treatment did not completely reverse the TNF- $\alpha$-induced decrease in adiponectin levels. In 3T3-L1 adipocytes, 32 or $48 \mathrm{~h}$ wash-off periods were required following 32 or $48 \mathrm{~h}$ TNF- $\alpha$ treatments, respectively. The pattern of ERK activation following TNF- $\alpha$ exposure and removal was similar to the pattern of adiponectin expression. Furthermore, ERK1/2 inhibition accelerated the recovery of adiponectin levels compared with the levels in the untreated control adipocytes. Therefore, the inhibitory effects of TNF- $\alpha$
\end{abstract}

Correspondence to: Professor Cheol-Young Park, Division of Endocrinology and Metabolism, Department of Internal Medicine, Kangbuk Samsung Hospital, Sungkyunkwan University School of Medicine, 108 Pyung-Dong, Jongno-Ku, Seoul 110-746, South Korea E-mail: cydoctor@chol.com

\section{${ }^{*}$ Contributed equally}

Abbreviations: ERK1/2, extracellular signal-regulated kinases 1 and 2; JNK, c-Jun N-terminal kinases; p38 MAPK, p38 mitogen-activated protein kinases; TNF- $\alpha$, tumor necrosis factor- $\alpha$

Key words: adiponectin, extracellular signal-regulated kinases 1 and 2 , obesity, tumor necrosis factor- $\alpha$, restoration on adiponectin levels in differentiated 3T3-L1 cells were fully reversed following a wash-out period equivalent to the TNF- $\alpha$ treatment time, potentially through the ERK 1/2 pathway.

\section{Introduction}

A chronic imbalance between energy intake and expenditure leads to obesity, which is characterized by an increased number and size of adipocytes. As an active endocrine organ, adipose tissue is part of an innate immune system capable of producing biologically active proteins referred to as adipokines, including leptin, tumor necrosis factor- $\alpha$ (TNF- $\alpha$ ), interleukin-6 (IL-6), resistin and adiponectin. Adipocyte-derived peptides are reciprocally reflected by energy homeostasis. Energy balance and body weight regulation affect the response and activities of adipose tissue by regulating adipokine production and secretion, all of which contribute to obesity-associated comorbidities and mortality (1-4).

The first adipose-derived proinflammatory mediator, TNF- $\alpha$, is well established as a major inflammatory adipokine that has been associated with adiposity, obesity, inflammation and the development of insulin resistance (4-6). The deleterious effects of TNF- $\alpha$ on insulin sensitivity result from its effects on lipolysis (7), adipocyte metabolism (8) and the insulin signaling network $(9,10)$. By contrast to TNF- $\alpha$, another adipose-secreted protein, adiponectin, is an established insulin-sensitizing adipokine with anti-inflammatory and anti-atherogenic properties $(11,12)$. Circulating levels of adiponectin and its synthesis in adipose tissue are decreased in patients and animals with obesity and type 2 diabetes $(13,14)$. In terms of the regulation of adiponectin, in vitro and in vivo studies have demonstrated the involvement of proinflammatory cytokines $(15,16)$. TNF- $\alpha$ directly inhibits adiponectin gene expression; however, this effect is reversed following stimulus removal (17). The mechanisms by which exposure and removal of obesity-inducing proinflammatory adipokines affect adiponectin remain to be fully elucidated.

Extensive studies have revealed that obesity is a state of chronic, low-grade inflammation, which may act as the potential link between adipose tissue expansion and obesity-induced health complications $(18,19)$. Proteins produced and secreted 
from adipose tissue fluctuate in response to energy balance, including weight change or adiposity size, which in turn reflects health outcome (20-22). However, to the best of our knowledge, the mechanisms by which metabolic stress from chronic energy imbalance increases proinflammatory cytokines and affects adiponectin remain elusive. In the present study, the mechanisms underlying the adverse effects of TNF- $\alpha$ on adiponectin were examined and the recovery time required to reverse the TNF- $\alpha$-induced decrease in adiponectin mRNA expression was determined.

\section{Materials and methods}

Materials. 3T3-L1 mouse fibroblast cells were obtained from the American Type Culture Collection (Manassas, VA, USA). Tissue culture reagents, including Dulbecco's modified Eagle's medium (DMEM), bovine calf serum (CS) and fetal bovine serum(FBS), were purchased from Invitrogen Life Technologies (Carlsbad, CA, USA). Antibodies against adiponectin, phospho-c-Jun N-terminal kinases (p-JNK; Thr183/Tyr185), total JNK (T-JNK), phospho-p38 mitogen-activated protein kinases (p-p38 MAPK; Thr180/Tyr182), total p38 MAPK (T-p38 MAPK), phospho-p44/42 MAPK [phospho-extracellular signal-related kinases 1 and 2 (p-ERK1/2); Thr202/Tyr204] and total p44/42 MAPK (T-ERK1/2) were rabbit monoclonal antibodies and were obtained from Cell Signaling Technology (Beverly, MA, USA). Unless otherwise noted, all other chemicals were purchased from Sigma (St. Louis, MO, USA).

Cell culture. Murine 3T3-L1 cells were plated in six-well plates and maintained in high glucose (HG)-DMEM containing $10 \%$ FBS, $100 \mathrm{U} / \mathrm{ml}$ penicillin and $100 \mu \mathrm{g} / \mathrm{ml}$ streptomycin. Two days following $100 \%$ confluence, preadipocytes were induced to differentiate by using MDI media containing $520 \mu \mathrm{M}$ isobutylmethylxanthine, $1 \mu \mathrm{M}$ dexamethasone and $1 \mu \mathrm{g} / \mathrm{ml}$ insulin in DMEM containing $10 \%$ fetal bovine serum (FBS). After two days, the medium was replaced with DMEM containing $10 \%$ FBS, antibiotics and insulin (insulin media). Until $>95 \%$ of the cells contained lipid droplets, HG-DMEM with $10 \%$ FBS was replaced every two days. Differentiated 3T3-L1 adipocytes were serum-starved in serum-free DMEM (free media) prior to the TNF- $\alpha$ treatment. Fig. 1 illustrates the experimental design for TNF- $\alpha$ treatment and the subsequent wash-off period with/without the inhibitor. The cells were treated with $10 \mathrm{ng} / \mathrm{ml} \mathrm{TNF}-\alpha$ for the indicated incubation times $[16,32 \mathrm{~h}$ or $48 \mathrm{~h}$ (Fig. 1A, C and F, respectively)], rinsed and then incubated with DMEM containing 10\% FBS (complete media) for the indicated periods according to TNF- $\alpha$ incubation time. In the adipocytes that received $16 \mathrm{~h}$ TNF- $\alpha$ treatment, the wash-off incubation was $16 \mathrm{~h}$ (Fig. 1B). TNF- $\alpha$-treated 3T3-L1 adipocytes for $32 \mathrm{~h}$ were cultured with complete media for either an additional $16 \mathrm{~h}$ (Fig. 1D) or $32 \mathrm{~h}$ (Fig. 1E). DMEM containing $10 \%$ FBS was used for either $16 \mathrm{~h}$ (Fig. 1G) or $48 \mathrm{~h}($ Fig. $1 \mathrm{H})$ following $48 \mathrm{~h}$ of TNF- $\alpha$ incubation.

Total RNA isolation and quantitative polymerase chain reaction ( $q P C R)$. Total RNA was isolated using the RNA Mini kit (Invitrogen Life Technologies) and cDNA was prepared using the high-capacity cDNA kit (Applied Biosystems, Foster City, CA, USA) following the manufacturer's instructions.
The reactions were incubated initially at $37^{\circ} \mathrm{C}$ for $60 \mathrm{~min}$ and subsequently at $95^{\circ} \mathrm{C}$ for $5 \mathrm{~min}$. The PCR primer design for qPCR was performed using the Universal Probe Library (UPL) software (Roche Applied Science, Mannheim, Germany). qPCR was conducted using the Roche real-time PCR master mix in combination with UPL in at least triplicate using a Roche Lightcycler 480 (Roche Applied Science) as follows: one cycle of pre-denaturation at $95^{\circ} \mathrm{C}$ for $10 \mathrm{~min}$, followed by 45 cycles of denaturation at $95^{\circ} \mathrm{C}$ for $10 \mathrm{sec}$ and annealing at $60^{\circ} \mathrm{C}$ for $20 \mathrm{sec}$, followed by one cycle of extension at $40^{\circ} \mathrm{C}$ for $30 \mathrm{sec}$. The expression levels were determined using the $\Delta \Delta \mathrm{Ct}$ method. The following sense and antisense primers were used for adiponectin: 5'-GGAGAGAAAGGAGATGCAGGT-3' and 5'-CTTTCCTGCCAGGGGTTC-3'; and for $\beta$-actin: 5'-ACTGCTCTGGCTCCTAGCAC-3' and 5'-CCACCGATCCACACAGAGTA-3'.

Western blot analysis. Differentiated 3T3-L1 adipocytes were serum-starved for $6 \mathrm{~h}$ prior to treatment. Cells were incubated with TNF- $\alpha$ for 16,32 or $48 \mathrm{~h}$. After the indicated time periods, the cells were washed with serum-free DMEM and re-fed with HG-DMEM containing the ERK1/2 inhibitor (PD98059; $50 \mu \mathrm{M}$ ) for the indicated times (Fig. 1). The cells were washed in ice-cold PBS and lysed in radioimmunoprecipitation assay lysis buffer (Amresco, Solon, OH, USA) containing freshly added protease inhibitor cocktail and phosphatase inhibitor cocktail (Sigma). The protein concentrations were measured using the bicinchoninic acid assay (Pierce Biotechnology, Inc., Rockford, IL, USA). Bromophenol blue and NuPage reducing agent (Invitrogen Life Technologies) were added to the cell lysates and this mixture was heated at $95^{\circ} \mathrm{C}$ for $5 \mathrm{~min}$. Equal protein levels were loaded into each lane of a 4-20\% SDS polyacrylamide gel. The proteins were separated by electrophoresis and transferred to a polyvinylidene difluoride membrane (Millipore, Billerica, MA, USA) with the Trans-Blot apparatus (Bio-Rad, Hercules, CA, USA). For immunoblotting, the membranes were blocked in $5 \%$ non-fat dry milk in TBST $(0.05 \%$ Tween $20,50 \mathrm{mM}$ Tris- $\mathrm{HCl}, \mathrm{pH} 7.5$ and $150 \mathrm{mM} \mathrm{NaCl}$ ), washed twice and incubated overnight with primary antibodies. After washing, the blots were incubated with horseradish peroxidase-conjugated secondary antibody for $1 \mathrm{~h}$ at room temperature. The signal was detected using the Amersham enhanced chemiluminescence plus system (Amersham-Pharmacia Biotech, Arlington Heights, IL, USA). Densitometric analysis of the individual bands was performed with Geliance Imaging software (PerkinElmer Life and Analytical Sciences, Boston, MA, USA). The data presented are representative of at least three independent experiments with similar results.

Statistical analysis. Data are expressed as mean \pm standard error (SE). Statistical significance was assessed using PASW Statistics 18 (SPSS, Inc., Chicago, IL, USA). Student's t-test or analysis of variance was performed to compare between the groups. $\mathrm{P}<0.05$ was considered to indicate a statistically significant difference between values.

\section{Results}

TNF- $\alpha$ inhibits mRNA expression of adiponectin in a dose-and time-dependent manner. To investigate the impact 


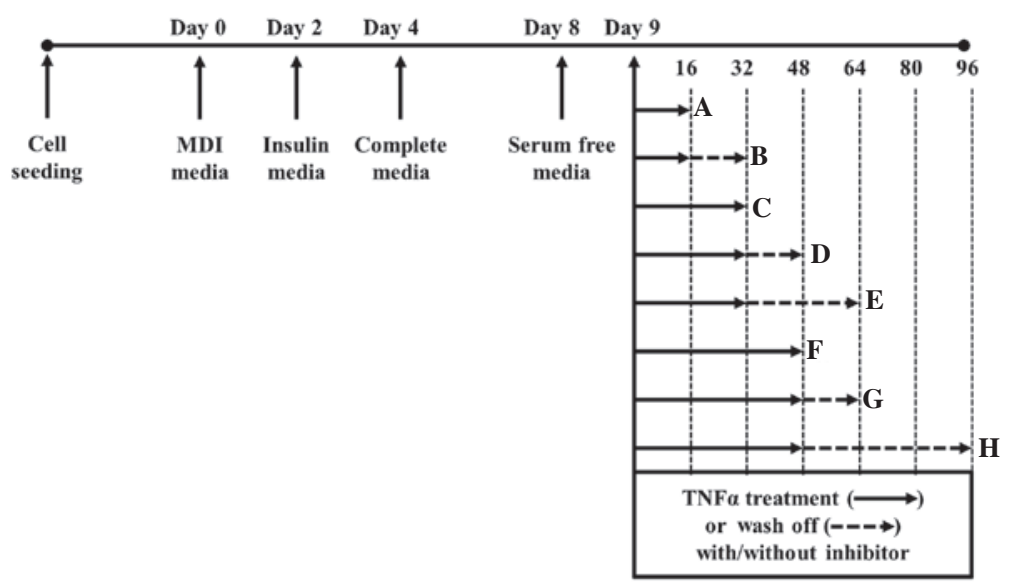

Figure 1. Schematic of the experimental design. 3T3-L1 cells were seeded and differentiated. Differentiated adipocytes were serum-starved for $6 \mathrm{~h}$ prior to TNF- $\alpha$ treatment (10 ng/ml). The cells were incubated with TNF- $\alpha$ for (A and B) $16 \mathrm{~h},(\mathrm{C}, \mathrm{D}, \mathrm{E}) 32 \mathrm{~h}$ or $(\mathrm{F}, \mathrm{G}, \mathrm{H}) 48 \mathrm{~h}$. After the indicated incubation times, 3T3-L1 cells were rinsed and re-fed with medium containing 10\% fetal bovine serum with/without inhibitors for (B, D, G) 16 h, (E) $32 \mathrm{~h}$ or (H) 48 h. Black arrow, TNF- $\alpha$ treatment; dotted arrow, wash-off period with/without inhibitor following TNF- $\alpha$ treatment. TNF- $\alpha$, tumor necrosis factor- $\alpha$.

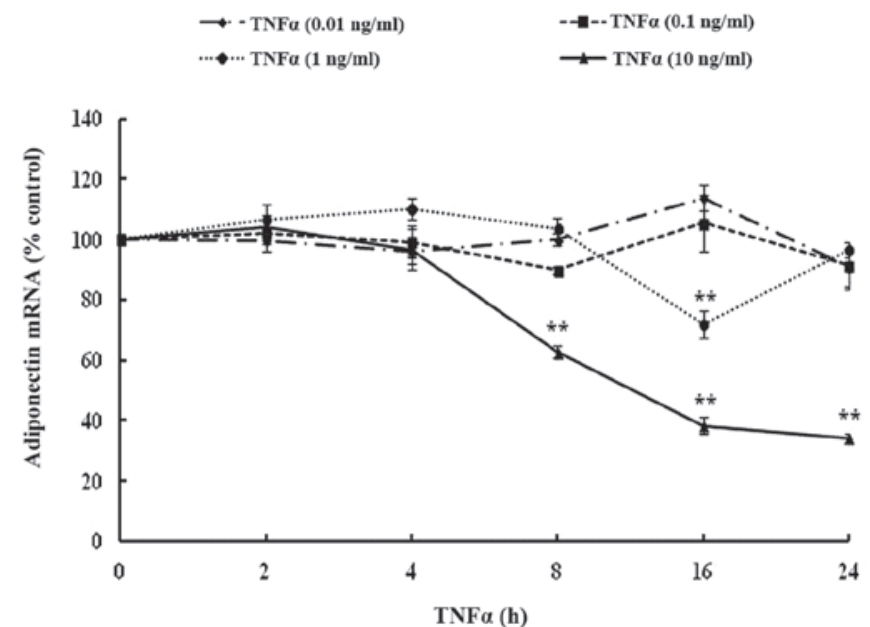

Figure 2. TNF- $\alpha$ decreases adiponectin mRNA expression. Differentiated 3T3-L1 adipocytes were serum-starved for $6 \mathrm{~h}$ and then treated with different doses $(0.01,0.1,1$ and $10 \mathrm{ng} / \mathrm{ml})$ and for different time periods $(2,4,8,16$ and $24 \mathrm{~h}$ ). The quantitative polymerase chain reaction products were normalized using $\beta$-actin levels for all samples. The results are expressed as the percentage of the control (untreated cells, $0 \mathrm{~h}$ ) from at least three experiments. ${ }^{* *} \mathrm{P}<0.01$, vs. the control. TNF- $\alpha$, tumor necrosis factor- $\alpha$.

of TNF- $\alpha$ on adiponectin, the mRNA expression was first measured in differentiated 3T3-L1 adipocytes. TNF- $\alpha$ significantly suppressed adiponectin gene expression in a dose- and time-dependent manner as compared with the control group. There was a significant reduction in mRNA levels by $37 \%$ following $8 \mathrm{~h}$ incubation at $10 \mathrm{ng} / \mathrm{ml}$ (Fig. 2). The maximal inhibition of adiponectin mRNA expression was $62 \%$, observed after $16 \mathrm{~h}$ incubation at a TNF- $\alpha$ concentration of $10 \mathrm{ng} / \mathrm{ml}$. There was no significant difference between the expression from the $16 \mathrm{~h}$ and $24 \mathrm{~h}$ incubation periods.

Inhibitory effect of TNF- $\alpha$ on gene expression of adiponectin is reversible in 3T3-L1 cells. To investigate the reversibility in the inhibitory effects of the proinflammatory adipokine, TNF- $\alpha$, on adiponectin mRNA expression, the effect of TNF- $\alpha$ at different exposure and removal time periods in differentiated 3T3-L1

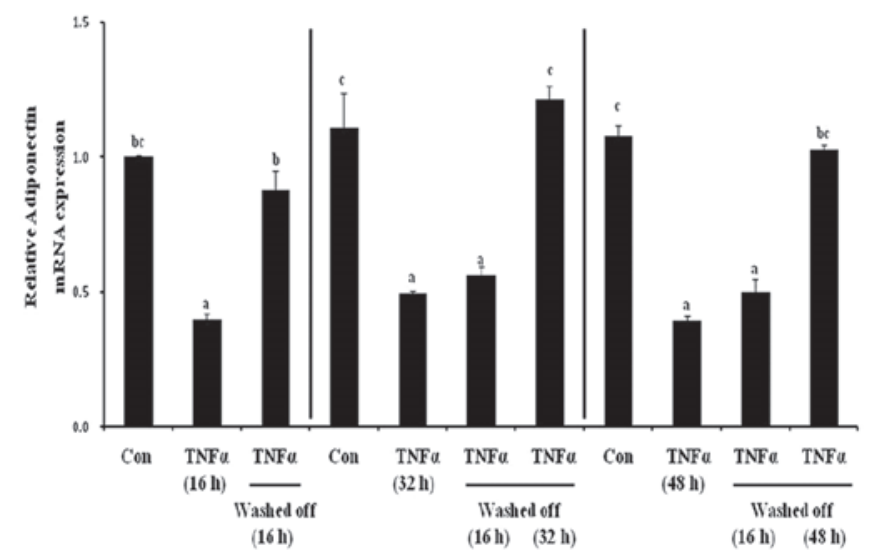

Figure 3. Inhibition of adiponectin gene expression by TNF- $\alpha$ is reversible. Differentiated adipocytes were treated with TNF- $\alpha$ for 16,32 and $48 \mathrm{~h}$ (columns 2,5 and 9). Following $6 \mathrm{~h}$ of serum starvation, high-glucose Dulbecco's modified Eagle's medium containing $10 \%$ fetal bovine serum was added. The additional wash-off incubation periods were $16 \mathrm{~h}$ for $16 \mathrm{~h} \mathrm{TNF}-\alpha$ treatment (column 3), 16 or $32 \mathrm{~h}$ for $32 \mathrm{~h} \mathrm{TNF- \alpha} \mathrm{treatment} \mathrm{(column} 6$ or 7) and 16 or 48 $\mathrm{h}$ for $48 \mathrm{~h}$ TNF- $\alpha$ treatment (column 10 or 11). Quantitative polymerase chain reaction was performed and the expression of adiponectin mRNA was normalized to $\beta$-actin expression. The results are expressed as mean \pm standard error. Bars with different letters show statistical difference among groups $(\mathrm{P}<0.05)$. TNF- $\alpha$, tumor necrosis factor- $\alpha$; Con, control.

adipocytes was examined. After three different TNF- $\alpha$ incubation periods (16, 32 and $48 \mathrm{~h}$ ), the cells were rinsed and re-fed with HG-DMEM containing 10\% FBS for an additional time as follows: i) $16 \mathrm{~h}$ wash-off incubation following $16 \mathrm{~h} \mathrm{TNF}-\alpha$ treatment; ii) 16 or $32 \mathrm{~h}$ recovery period following $32 \mathrm{~h} \mathrm{TNF}-\alpha$ treatment and iii) 16 or $48 \mathrm{~h}$ TNF- $\alpha$ removal following $48 \mathrm{~h}$ TNF- $\alpha$ exposure (Fig. 1). Chronic TNF- $\alpha$ incubation significantly reduced adiponectin gene expression by $60 \%$ compared with the untreated control cells (Fig. 3). Following removal of TNF- $\alpha$ from the medium, there was a time-dependent reversal of the TNF- $\alpha$-mediated reduction in adiponectin levels. In Fig. 3, column 3 , the $16 \mathrm{~h}$ wash-off phase completely reversed the decrease in adiponectin levels following $16 \mathrm{~h}$ of TNF- $\alpha$ treatment, returning to the levels observed in the control. The $16 \mathrm{~h}$ TNF- $\alpha$ withdrawal did not induce a significant effect (column 6), but the 

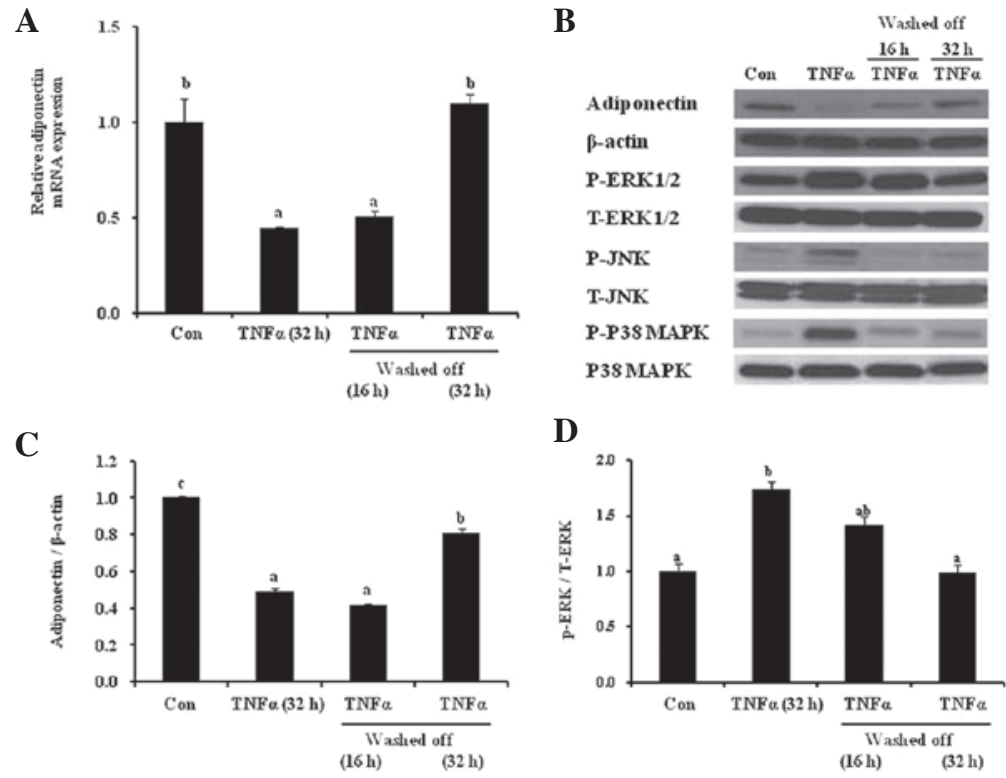

Figure 4. Recovery phase following TNF- $\alpha$ treatment restores adiponectin levels and ERK activation. Differentiated adipocytes were treated with TNF- $\alpha$ $(10 \mathrm{ng} / \mathrm{ml})$ for $32 \mathrm{~h}$ and then the cells were subjected to a wash-off period (16 or $32 \mathrm{~h}$ ). (A) mRNA expression of adiponectin was assessed using quantitative polymerase chain reaction. (B) The cell lysates were analyzed by western blot analysis and probed for adiponectin, $\beta$-actin, p-JNK (Thr183/Tyr185), T-JNK, p-p38 MAPK (Thr180/Tyr182), T-p38 MAPK, p-ERK1/2 (Thr202/Tyr204) and T-ERK1/2. The signal density was quantified and expressed as (C) adiponectin/ $\beta$-actin and (D) phospho-/total ERK. The results are expressed as the mean \pm standard error. Different letters indicate statistical difference $(\mathrm{P}<0.05)$. TNF- $\alpha$, tumor necrosis factor- $\alpha$; MAPK, mitogen-activated protein kinases; JNK, c-Jun N-terminal kinase; ERK1/2, extracellular signal-related kinase 1 and 2; p, phospho; T, total.

A

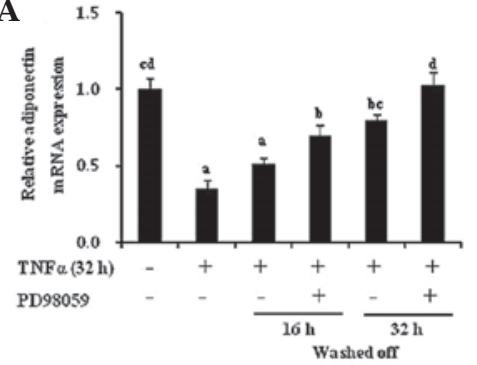

C

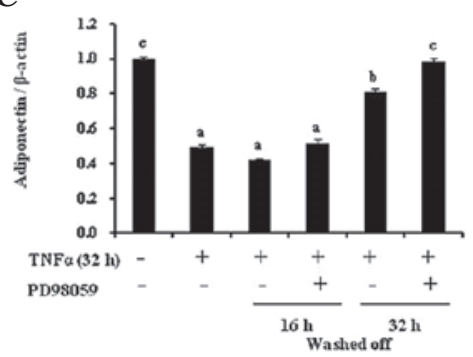

B

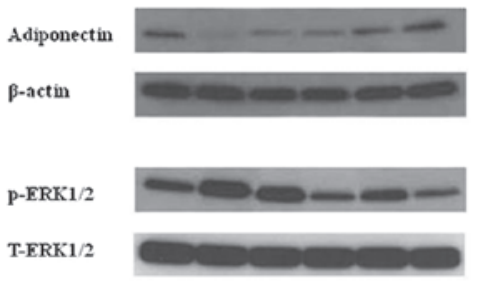

D

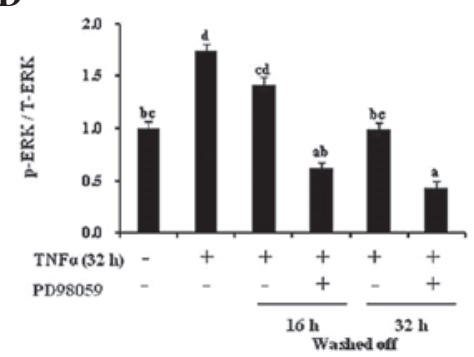

Figure 5. ERK inhibition is involved in the TNF- $\alpha$-induced decline and recovery of adiponectin expression in adipocytes. The $6 \mathrm{~h}$ serum-starved 3T3-L1 adipocytes were treated with TNF- $\alpha$ for $32 \mathrm{~h}$, rinsed with DMEM and co-treated with PD98059 $(50 \mu \mathrm{M})$ for the additional incubation period. (A) The gene expression of adiponectin was determined by quantitative polymerase chain reaction and normalized to $\beta$-actin expression for all of the samples. (B) Western blot analysis for adiponectin, $\beta$-actin, p-ERK1/2 and T-ERK1/2 was performed. Densitometric analysis of (C) adiponectin or (D) p-ERK1/2 was normalized to the expression of $\beta$-actin or T-ERK1/2, respectively. The results are expressed as the mean \pm standard error. Different letters indicate statistical difference $(\mathrm{P}<0.05)$. TNF- $\alpha$, tumor necrosis factor- $\alpha$; MAPK, mitogen-activated protein kinases; JNK, c-Jun N-terminal kinases; ERK, extracellular signal-related kinases; DMEM, Dulbecco's modified Eagle's medium; p, phospho; T, total.

$32 \mathrm{~h}$ wash-off period fully reversed the decrease in adiponectin expression following the $32 \mathrm{~h} \mathrm{TNF}-\alpha$ treatment (column 7). Similar results were observed for $48 \mathrm{~h}$ TNF- $\alpha$ incubation, a $16 \mathrm{~h}$ restoration did not have a significant impact (column 10); however, a $48 \mathrm{~h}$ wash-off period fully reversed the negative effect of TNF- $\alpha$ on adiponectin mRNA expression (column 11). These findings suggested that the inhibitory effect of TNF- $\alpha$ on adiponectin is reversible and the adverse effects are dependent on the length of TNF- $\alpha$ exposure and the subsequent recovery period.

Length of recovery phase affects TNF- $\alpha$-induced MAPK activation in differentiated 3T3-L1 adipocytes. There is a positive 
correlation between TNF- $\alpha$ and activation of three different MAPKs, JNK, ERK1/2 and p38 MAPK, in the development of obesity-associated insulin resistance. Therefore, in the present study, the effect of a wash-off period following exposure to the proinflammatory cytokine TNF- $\alpha$ and the subsequent activation of MAPKs was examined. Similar to the pattern of adiponectin mRNA expression (Fig. 4A), the decrease in adiponectin protein expression after $32 \mathrm{~h}$ treatment with TNF- $\alpha$ was completely reversed following an equivalent (32 h) wash-out period (Fig. 4B and C). In addition, the reduction in adiponectin levels following $32 \mathrm{~h} \mathrm{TNF-} \alpha$ treatment was concomitantly accompanied by activation of JNK, ERK1/2 and p38 MAPK, expressed as phospho-protein/total protein. A $16 \mathrm{~h}$ wash-off phase following $32 \mathrm{~h}$ TNF- $\alpha$-treatment reversed the TNF- $\alpha$-activated JNK and p38 MAPK, but not ERK1/2 (Fig. 4B). ERK1/2 activation was attenuated following a $32 \mathrm{~h}$ wash-off period (Fig. 4B and D). This restoration pattern of ERK1/2 in response to chronic TNF- $\alpha$ exposure and wash-off was similar to that of adiponectin protein and mRNA expression. These results suggested that the effect of TNF- $\alpha$ on adiponectin expression was reversible through ERK activation.

Recovery phase facilitates TNF- $\alpha$-induced suppression of adiponectin expression via ERK1/2 activation. To delineate the effects of the ERK pathway on the recovery of adiponectin expression following TNF- $\alpha$ exposure, 3T3-L1 adipocytes were treated with TNF- $\alpha(32 \mathrm{~h}, 10 \mathrm{ng} / \mathrm{ml})$ and co-treated with the ERK inhibitor PD98059 $(50 \mu \mathrm{M})$ in HG-DMEM containing $10 \%$ FBS for an additional restoration time period (16 or $32 \mathrm{~h}$ ) (Fig. 5). The $16 \mathrm{~h}$ recovery period did not completely reverse the inhibitory effects of $32 \mathrm{~h} \mathrm{TNF}-\alpha$ treatment, whereas the use of PD98059 during this recovery period fully restored adiponectin levels to the control levels. The recovery effect of the ERK inhibitor on adiponectin levels was equivalent to the effect of the $32 \mathrm{~h}$ wash-off time without the inhibitor. However, there were no additional effects on restoration in the $32 \mathrm{~h}$ restoration phase with PD98059. Furthermore, the addition of the ERK1/2 inhibitor during the $16 \mathrm{~h}$ restoration period significantly increased the protein expression of adiponectin compared with the control and concomitantly reduced ERK activation.

\section{Discussion}

The results of the present study demonstrated the regulation and restoration of adiponectin expression by an obesity-induced proinflammatory adipokine in adipocytes. It was identified that TNF- $\alpha$ significantly decreased the expression of both adiponectin protein and mRNA, and this inhibitory effect was completely reversed in a time-dependent manner. In order to reverse the inhibitory effects of TNF- $\alpha$ on adiponectin, the reversal periods were required to be at least as long as the TNF- $\alpha$ treatment period. Concurrently, it was identified that the reversal pattern of ERK activation was consistent with the TNF- $\alpha$-induced changes in adiponectin expression. Further investigation revealed that the addition of an ERK inhibitor during restoration following chronic $\mathrm{TNF}-\alpha$ treatment resulted in a complete reversal of the inhibitory effects of the proinflammatory cytokine on adiponectin, and the recovery was notably quicker than that in the absence of the ERK inhibitor.
These results suggested that the ERK pathway may modulate recovery of adiponectin levels following TNF- $\alpha$ exposure.

TNF- $\alpha$ is the strongest candidate for the link between obesity and insulin resistance. There is a close association between proinflammatory adipokines and the deleterious effects of obesity-associated comorbidities, and numerous studies have described the inhibitory effects of TNF- $\alpha$ on the regulation of another cytokine, adiponectin $(16,17,23)$. Adiponectin deletion results in increased TNF- $\alpha$ expression and diet-induced insulin resistance. Adiponectin administration in adiponectin knockout transgenic mice ameliorates high TNF- $\alpha$ concentrations in the plasma and adipose TNF- $\alpha$ mRNA expression, and also increases insulin sensitivity (24). Furthermore, an in vitro study demonstrated that the inhibitory effect of TNF- $\alpha$ on adiponectin gene expression is fully reversible following the removal of TNF- $\alpha$ (17). These studies demonstrated that TNF- $\alpha$ and adiponectin antagonistically regulate each other and in turn affect obesity-associated insulin sensitivity. As expected, in the present study, TNF- $\alpha$ induced a significant reduction in adiponectin mRNA expression in a dose- and time-dependent manner. As reported in a previous investigation, it was also identified that the inhibitory effects of TNF- $\alpha$ on adiponectin expression are reversible. Furthermore, this restoration is dependent on the TNF- $\alpha$ incubation time in 3T3-L1 adipocytes, as the decrease in adiponectin levels following $16 \mathrm{~h}$ TNF- $\alpha$ treatment was completely reversed after a $16 \mathrm{~h}$ restoration phase. In 3T3-L1 cells treated with TNF- $\alpha$ for 32 or $48 \mathrm{~h}$, a $16 \mathrm{~h}$ wash-off period resulted in partial restoration of 55 and $45 \%$, respectively, compared with the untreated control adipocytes. It appears that, in order to fully reverse the inhibitory effect of TNF- $\alpha$ on adiponectin expression, the reversal period is required to be at least as long as the TNF- $\alpha$ treatment period. These data indicated that normalization of the proinflammatory cytokine, TNF- $\alpha$, by weight loss, decreased adiposity or improved energy homeostasis may increase adiponectin levels and thereby reduce obesity-associated comorbidities.

In the development of obesity-associated insulin resistance, the direct actions of TNF- $\alpha$ on insulin signaling and insulin action occur via the activation of ERK1/2, p38 MAPK and JNK (25), all of which suppress adiponectin levels (26,27). As previously reported, in the present study, chronic TNF- $\alpha$ exposure in 3T3-L1 adipocytes activated JNK, ERK1/2 and p38 MAPK. However, the reversal of ERK activation only matched the TNF- $\alpha$-associated decrease and restoration of adiponectin expression. The use of PD98059 had favorable effects on adiponectin recovery, as the restoration of the TNF- $\alpha$-induced decrease in adiponectin levels was accelerated in the presence of PD98059. This evidence indicated that ERK activation may regulate the recovery duration following chronic cytokine exposure.

The present study was limited by the fact that it did not address how exposure to TNF- $\alpha$ and withdrawal may affect body weight, adiposity and whole body insulin sensitivity by modulating adiponectin expression and the ERK pathway. Therefore, further study is required to demonstrate this using an in vivo model. However, the present study provided evidence that the inhibitory effect of TNF- $\alpha$ on adiponectin mRNA expression was reversible depending on the length of the wash-off phase and ERK activation in adipocytes. The 
restoration of adiponectin following chronic exposure to TNF- $\alpha$ was accelerated by the presence of an ERK inhibitor. In conclusion, the present study suggested that reduction of TNF- $\alpha$ by energy balance, weight loss, decreased adiposity or blockage of TNF- $\alpha$ or its receptors, and the inhibition of ERK activation may increase adiponectin levels and thereby result in increased insulin sensitivity.

\section{Acknowledgements}

The present study was partially supported by the Korean Diabetes Association (Won Jun Kim, 2010).

\section{References}

1. Trayhurn P and Beattie JH: Physiological role of adipose tissue: white adipose tissue as an endocrine and secretory organ. Proc Nutr Soc 60: 329-339, 2001.

2. Frühbeck G, Gómez-Ambrosi J, Muruzábal FJ, et al: The adipocyte: a model for integration of endocrine and metabolic signaling in energy metabolism regulation. Am J Physiol Endocrinol Metab 280: E827-E847, 2001.

3. Berg AH and Scherer PE: Adipose tissue, inflammation, and cardiovascular disease. Circ Res 96: 939-949, 2005.

4. Hotamisligil GS, Arner P, Caro JF, et al: Increased adipose tissue expression of tumor necrosis factor-alpha in human obesity and insulin resistance. J Clin Invest 95: 2409-2415, 1995.

5. Hotamisligil GS, Shargill NS and Spiegelman BM: Adipose expression of tumor necrosis factor-alpha: direct role in obesity-linked insulin resistance. Science 259: 87-91, 1993.

6. Kern PA, Ranganathan S, Li C, et al: Adipose tissue tumor necrosis factor and interleukin-6 expression in human obesity and insulin resistance. Am J Physiol Endocrinol Metab 280: E745-E751, 2001.

7. Souza SC, Palmer HJ, Kang YH, et al: TNF-alpha induction of lipolysis is mediated through activation of the extracellular signal related kinase pathway in 3T3-L1 adipocytes. J Cell Biochem 89: 1077-1086, 2003.

8. Zhang B, Berger J, Hu E, et al: Negative regulation of peroxisome proliferator-activated receptor-gamma gene expression contributes to the antiadipogenic effects of tumor necrosis factor-alpha. Mol Endocrinol 10: 1457-1466, 1996.

9. Hotamisligil GS, Budavari A, Murray D, et al: Reduced tyrosine kinase activity of the insulin receptor in obesity-diabetes. Central role of tumor necrosis factor-alpha. J Clin Invest 94: 1543-1549, 1994.

10. Hotamisligil GS, Peraldi P, Budavari A, et al: IRS-1-mediated inhibition of insulin receptor tyrosine kinase activity in TNF-alpha- and obesity-induced insulin resistance. Science 271: 665-668, 1996.

11. Yamauchi T, Hara K, Kubota N, et al: Dual roles of adiponectin/Acrp30 in vivo as an anti-diabetic and anti-atherogenic adipokine. Curr Drug Targets Immune Endocr Metabol Disord 3: 243-253, 2003
12. Wu X, Motoshima $\mathrm{H}$, Mahadev $\mathrm{K}$, et al: Involvement of AMP-activated protein kinase in glucose uptake stimulated by the globular domain of adiponectin in primary rat adipocytes. Diabetes 52: 1355-1363, 2003.

13. Hotta K, Funahashi T, Bodkin NL, et al: Circulating concentrations of the adipocyte protein adiponectin are decreased in parallel with reduced insulin sensitivity during the progression to type 2 diabetes in rhesus monkeys. Diabetes 50: 1126-1133, 2001.

14. Hotta K, Funahashi T, Arita Y, et al: Plasma concentrations of a novel, adipose-specific protein, adiponectin, in type 2 diabetic patients. Arterioscler Thromb Vasc Biol 20: 1595-1599, 2000.

15. Lihn AS, Richelsen B, Pedersen SB, et al: Increased expression of TNF-alpha, IL-6, and IL-8 in HALS: implications for reduced adiponectin expression and plasma levels. Am J Physiol Endocrinol Metab 285: E1072-E1080, 2003.

16. Ajuwon KM and Spurlock ME: Adiponectin inhibits LPS-induced NF-kappaB activation and IL-6 production and increases PPARgamma2 expression in adipocytes. Am J Physiol Regul Integr Comp Physiol 288: R1220-R1225, 2005.

17. Fasshauer M, Klein J, Neumann S, et al: Hormonal regulation of adiponectin gene expression in 3T3-L1 adipocytes. Biochem Biophys Res Commun 290: 1084-1089, 2002.

18. Lee YH and Pratley RE: The evolving role of inflammation in obesity and the metabolic syndrome. Current Diab Rep 5: 70-75, 2005.

19. Heilbronn LK and Campbell LV: Adipose tissue macrophages, low grade inflammation and insulin resistance in human obesity. Curr Pharm Des 14: 1225-1230, 2008

20. Monzillo LU, Hamdy O, Horton ES, et al: Effect of lifestyle modification on adipokine levels in obese subjects with insulin resistance. Obes Res 11: 1048-1054, 2003.

21. Fontana L, Eagon JC, Trujillo ME, et al: Visceral fat adipokine secretion is associated with systemic inflammation in obese humans. Diabetes 56: 1010-1013, 2007.

22. Fain JN, Madan AK, Hiler ML, et al: Comparison of the release of adipokines by adipose tissue, adipose tissue matrix, and adipocytes from visceral and subcutaneous abdominal adipose tissues of obese humans. Endocrinology 145: 2273-2282, 2004.

23. Kern PA, Di Gregorio GB, Lu T, et al: Adiponectin expression from human adipose tissue relation to obesity, insulin resistance, and tumor necrosis factor-alpha expression. Diabetes 52: 1779-1785, 2003.

24. Maeda N, Shimomura I, Kishida K, et al: Diet-induced insulin resistance in mice lacking adiponectin/ACRP30. Nat Med 8: 731-737, 2002.

25. Fujishiro M, Gotoh Y,Katagiri H, et al: Three mitogen-activated protein kinases inhibit insulin signaling by different mechanisms in 3T3-L1 adipocytes. Mol Endocrinol 17: 487-497, 2003.

26. Kim KY, Kim JK, Jeon JH, et al: c-Jun N-terminal kinase is involved in the suppression of adiponectin expression by TNF-alpha in 3T3-L1 adipocytes. Biochem Biophys Res Commun 327: 460-467, 2005.

27. Zhao T, Hou M, Xia M, et al: Globular adiponectin decreases leptin-induced tumor necrosis factor-alpha expression by murine macrophages: involvement of cAMP-PKA and MAPK pathways. Cell Immunol 238: 19-30, 2005. 